\title{
Research Paper \\ Estimation of the Income Elasticity of Health Costs in Iran
}

\author{
*Abolghasem Golkhandan ${ }^{1}$ (1) \\ 1. PhD. Candidate in Economics, Department of Business Economics, Faculty of Economics and Administration, Lorestan University, \\ Khorramabad, Iran.
}

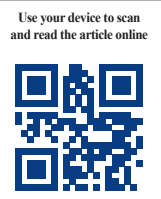

Crtation Golkhandan, A. (2018). Estimation of the Income Elasticity of Health Costs in Iran. Quarterly Journal of the Macro and Strategic Policies, 6(3), 376-397. http://dx.doi.org/10.32598/ JMSP.6.3.376

\section{doi : http://dx.doi.org/10.32598/JMSP.6.3.376}

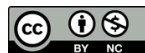

Funding: See Page 393

Received: 18 Aug 2016 Accepted: 17 Mar 2018 Available Online: 23 Sep 2018

Key words:

Health costs, Income, Bayesian approach, Model uncertainty, Iran

\section{A B STR ACT}

Estimation of the income elasticity of health costs is important in determining the policies adopted in health sector. Previous studies in this area has been done with the assumption of the model certainty; while ignoring the problem of model uncertainty can lead to bias and overlooking parameters that result is inappropriate forecasts and incorrect statistical inference. Thus, the main objective of this study is to estimate income elasticity of health costs in Iran under uncertainty of model from 1979 to 2013. For this purpose, the Bayesian approach was used because of its favorable characteristics for the assumption of model uncertainty. Estimation of 40000 regression and Bayesian averaging from the coefficients of the 24 effective variables on per capita costs of the health sector shows that per capita income is the most important determinant of these costs. The income elasticity of health costs is estimated approximately 0.7 , that shows health an essential commodity in Iran. Accordingly, we propose that health services be financed by governmental budget that is necessary in health services and provision. Based on other results, the effects of urbanization, per capita public health costs, dependency ratio, physicians per capita and the unemployment rate per capita are certain and strong on health sector costs in the long run. JEL Classification: C11, I1, J2

* Corresponding Author:

Abolghasem Golkhandan, PhD. Candidate

Address: Department of Business Economics, Faculty of Economics and Administration, Lorestan University, Khorramabad, Iran.

Tel: +98 (918) 3666361

E-mail: golkhandana@gmail.com 


\section{برآورد نوسانات كشش درآمدى مخارج سلامت در ايران}

(10) · موالقاسم كل خندان

ا - دانشجوى دكتراى اقتصاد بخش عمومى، كروه اقتصاد بازركائى، دانشكده علوم اقتصادى و ادارى، دانشكاه لرستان، خرمآباد، ايران.

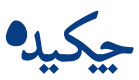

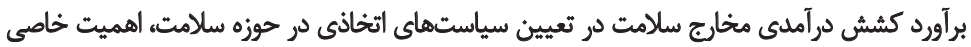

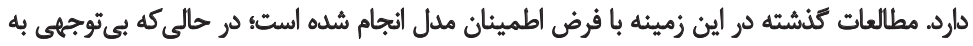

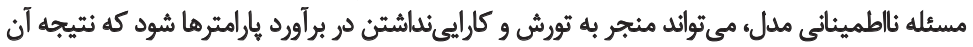

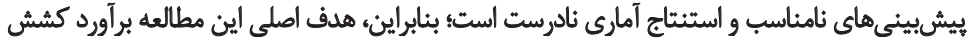

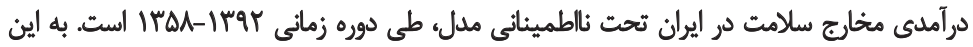

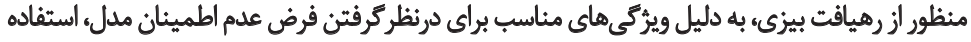

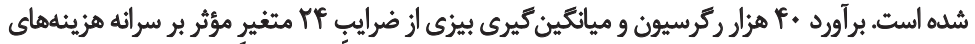

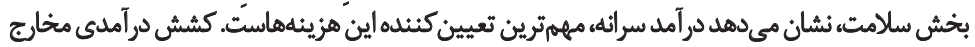

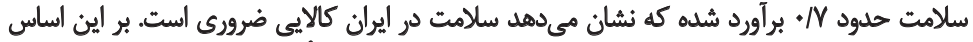

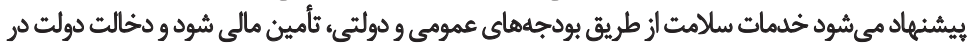

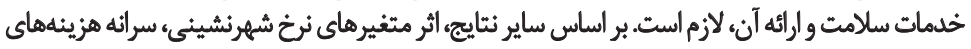

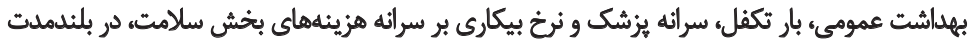

$$
\text { حتمى و قوى استي. }
$$

طبقلبئدى
تاريخ دريافت: Tr مرداد هوج"

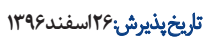

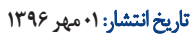

: Soflg

مخارج سلامته

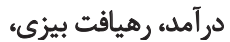

ناطمينانى مدل، ايران بئن

* نويسنده مسئول:

إبوالقاسيم كر خدندان

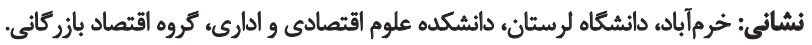

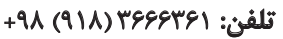

golkhandana@gmail.com بلغن الكثرونيكي: 


\section{dalo}

يكى از جالش هاى اساسى حوزه اقتصاد سلامت، شناسايى عوامل مؤثر بر هزينههاى بخش سلامت است. مرورى

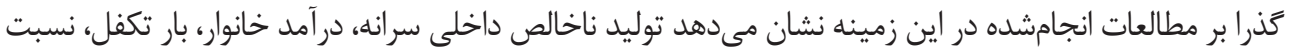

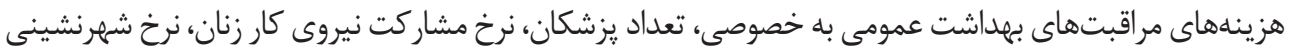

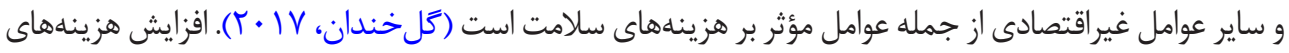

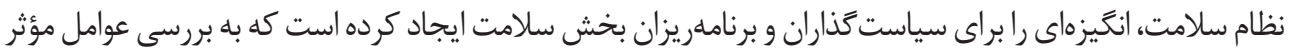

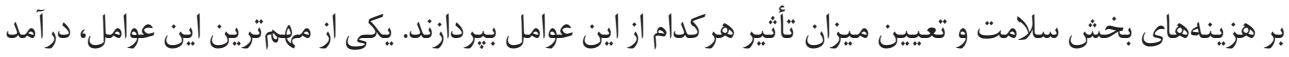

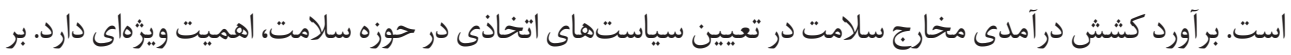
اين اساس، جنانجه كشش درآمدى مخارج سلامت بزرى

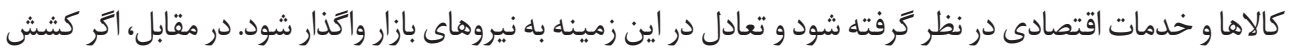
در آمدى مخارج سلامت كوجى

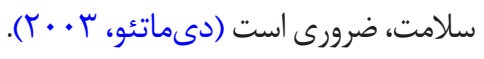

با توجه به توضيحات مذكور، هدف اصلى اين مقاله بررسى ميزان اهميت و جايگاه درآمد در تعيين هزينهانى

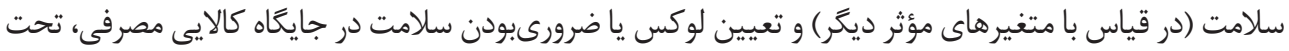

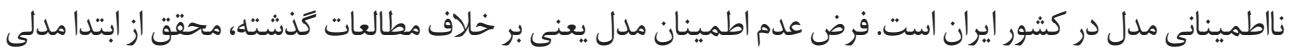

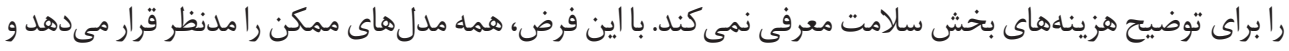

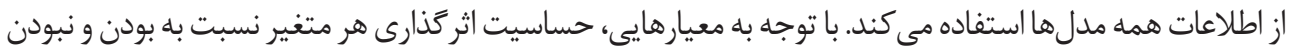

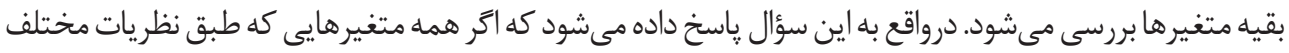

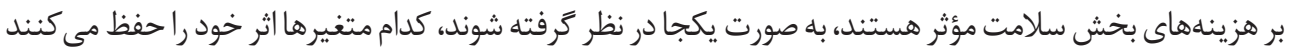

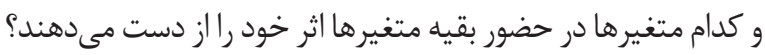

در بررسى حساسيت يك متغير، اگر حضور عوامل ديخر منجر به بـىمعناشدن يا تغيير علامت اثر آن متغير شود،

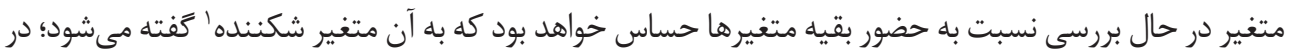

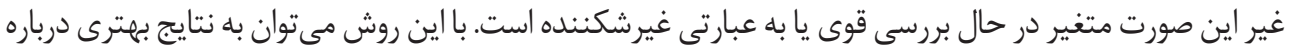

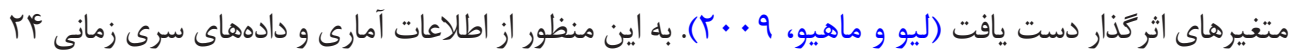

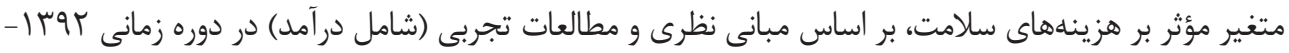

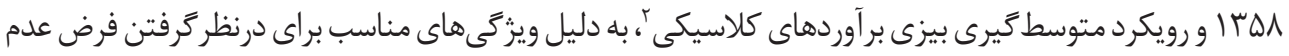

2. Bayesian Averaging of Classical Estimates (BACE) 


\section{1- إديات موضوع}

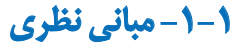

بررسى عوامل تعيين كننده هزينههاى سلامت، موضوعى است كه از دهه • 19V اقتصاددانان به آن توجه

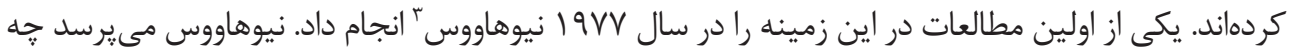

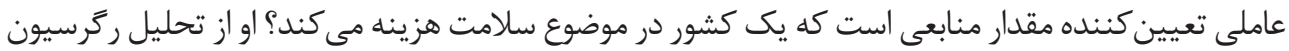

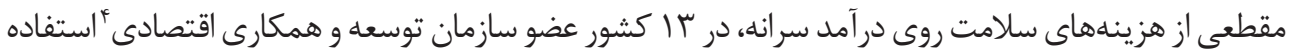

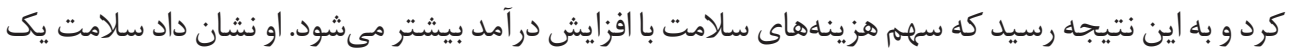
كالاى با كشش درد آمدى بزرى (19VV) (19V)

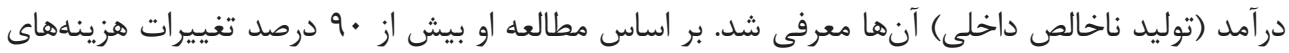

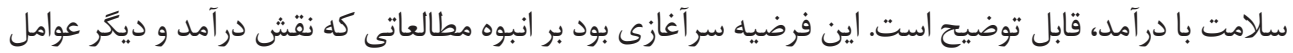
مؤثر بر مخارج سلامت را بررسى كردهاند.

يس از مطالعه نيوهاووس، مطالعات گستردهاى در راستاى اندازهيرى شدت و بزرگى اين تأثيرگذارى در

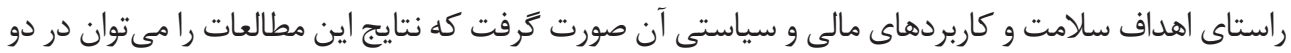

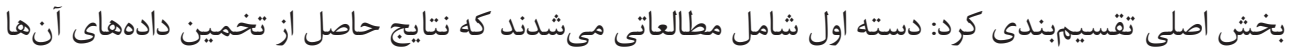

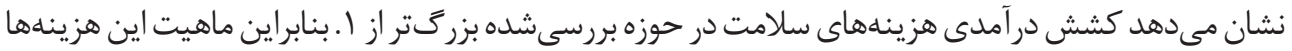

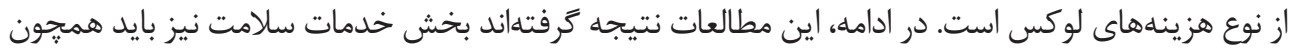

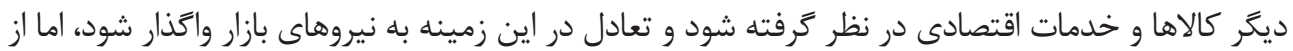

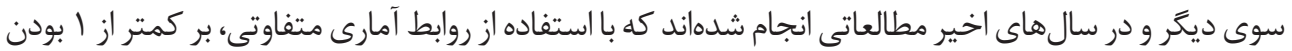

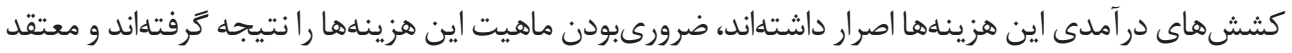

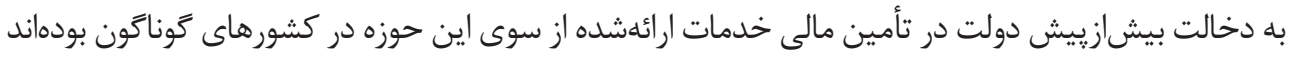

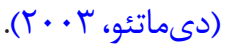

اولينبار نيوهاووس (9VV) (19V) در مطالعه خود به ماهيت دوكانه خدمات سلامت در كشورهاى صنعتى و

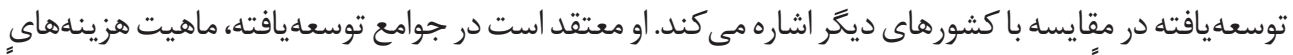

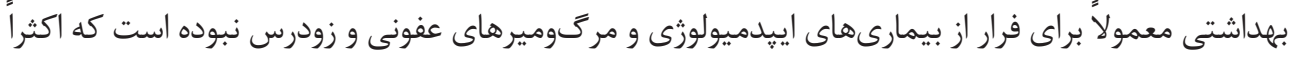

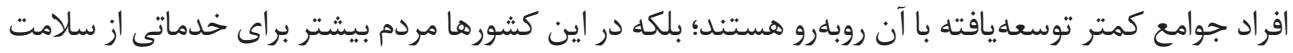

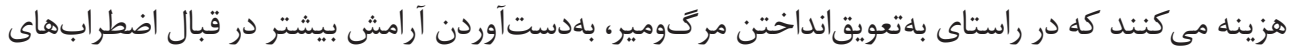
زندگى و تشخيص هزئه بهتر و دقيقتر است كه البته وجه مشترك همه اين خدمات نياز به تكنولوزى دهاى بهرتر

\section{Newhouse}

4. Organization for Economic Co-operation and Development (OECD) 
و كرانتر است. اين موضوع نيز از نظر توسعه اقتصادى تا حدودى مى تواند باعث كششهاى مخد متفاوت در آمدى در

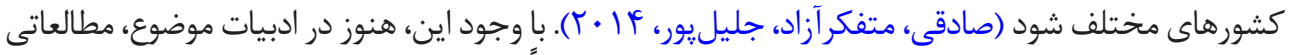

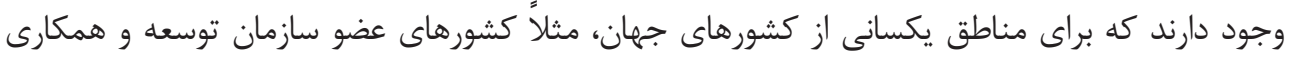

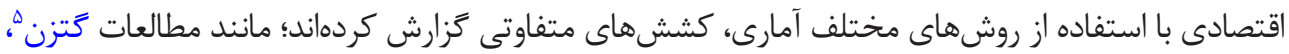

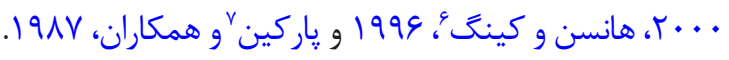

در بررسى عوامل مؤثر بر هزينههاى بخش سلامت، برخى عوامل غيردر آمدى ديخر در توضيح نوسانات

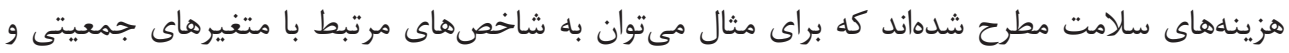

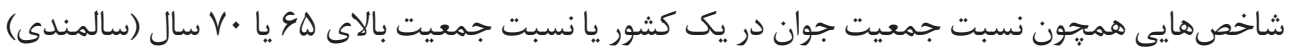

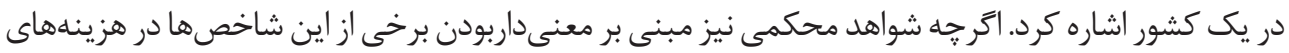

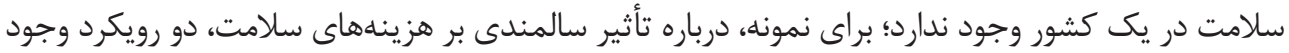

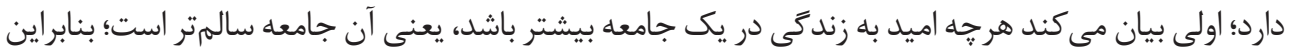

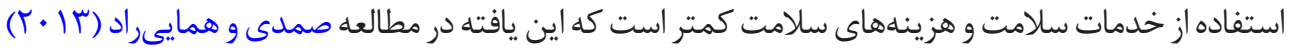

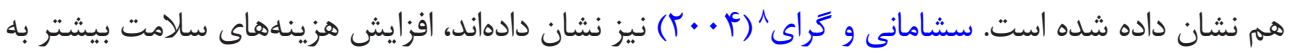

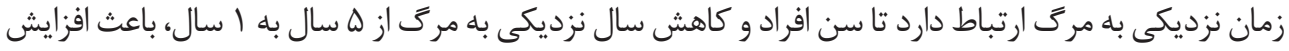

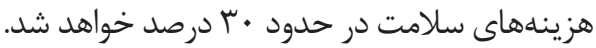

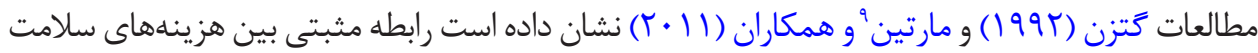

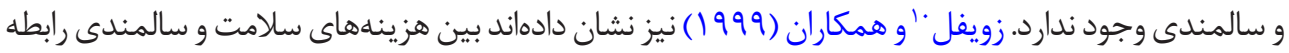

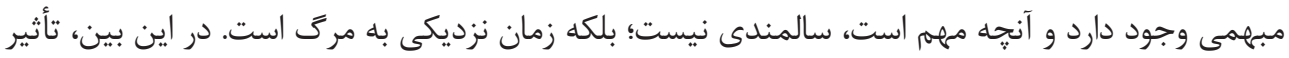

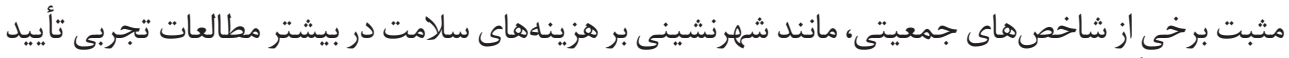

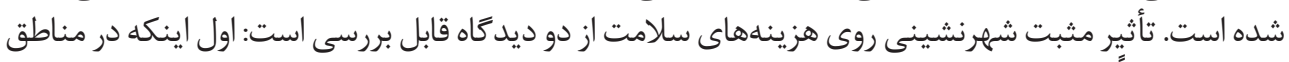

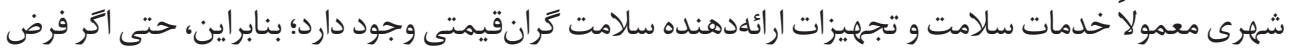

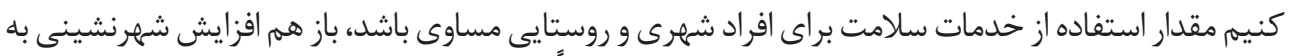

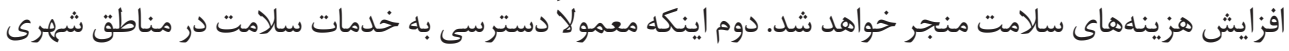

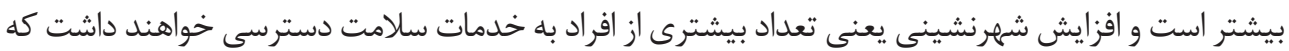

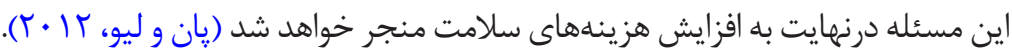
از متغيرهاى ديخرى كه در ادبيات موضوع عامل توضيحدهنده تفاوتهاى موجود در سطح هزينههاى سلامت است، سمهم واندازه هزينه كرد بخش عمومى و دولتى اقتصاد در حوزه سلامت است. در اين خصوص نيز نتئن نتايج

5. Getzen

6. Hansen and King

7. Parkin

8. Seshamani and Gray

9. Martín

10. Zweifel 


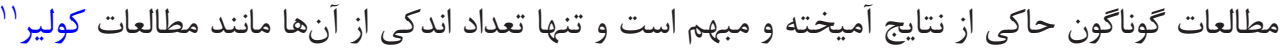

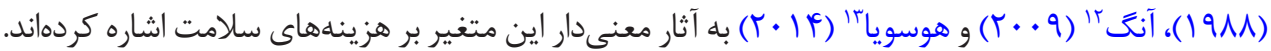

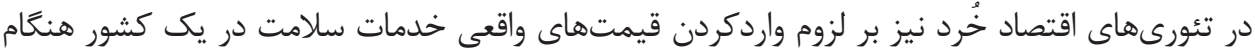

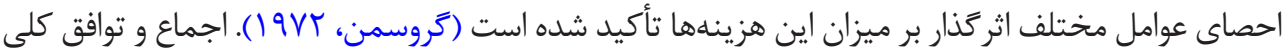

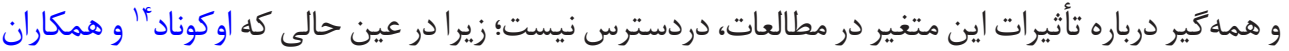

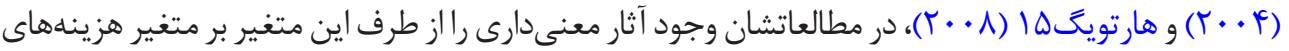

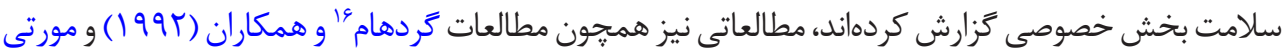

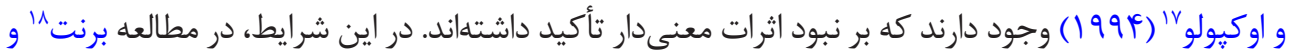

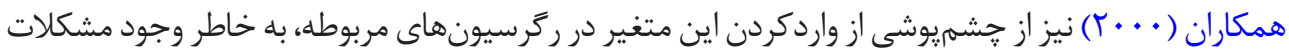

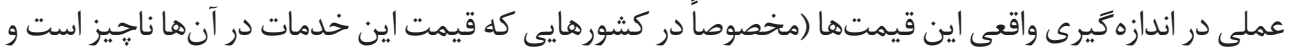

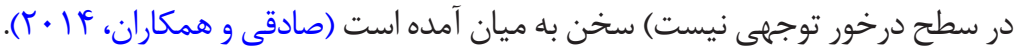

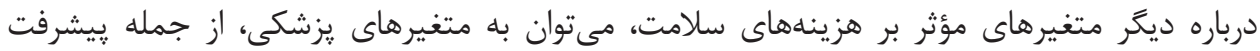

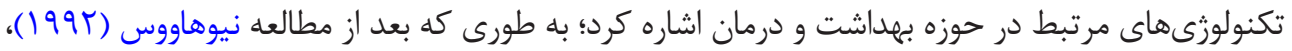

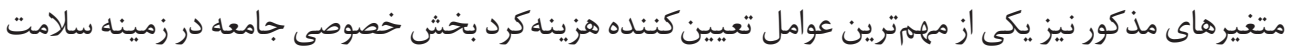

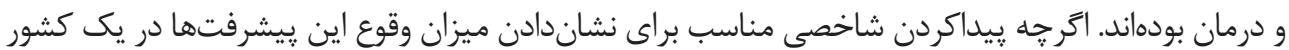

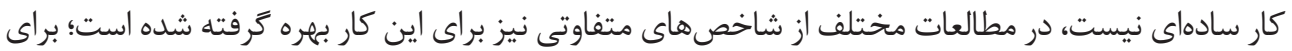

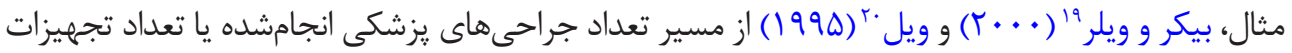

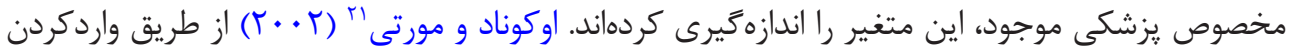

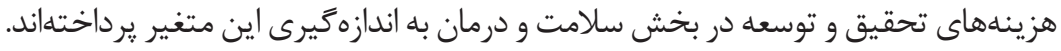

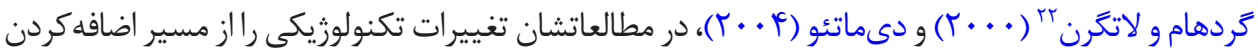

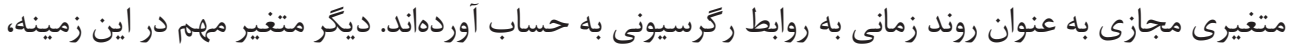

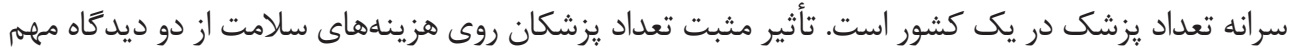

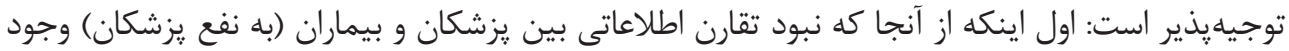

11. Culyer

12. Ang

13. Hosoya

14. Okunade

15. Hartwig

16. Gerdham

17. Murthy and Ukpolo

18. Berndt

19. Bater and Wheeler

20. Weil

21. Okunade and Murthy

22. Gerdham and Lothgren 
دارد؛ بنابراين، زمانى كه تعداد يزشكان در يك منطقه زياد شود، سرانه مراجعه افراد به هركدام از يزشكان

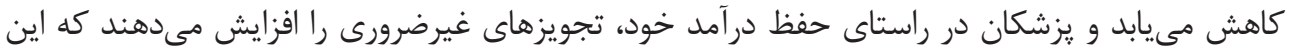

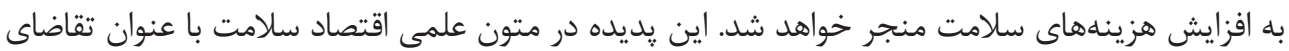

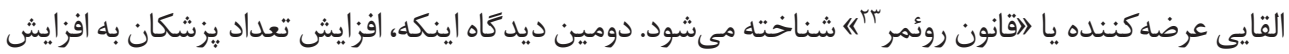

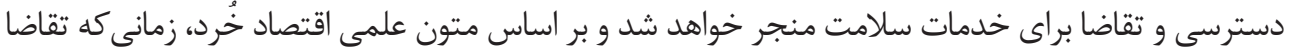

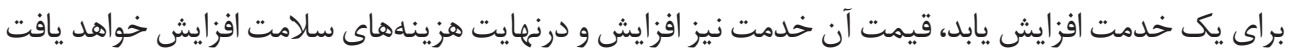

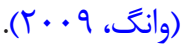

در يك جمعبندى كلى مى توان كفت با وجودى كه در طيف كستردهاى از مطالعات كه اكثراً نيز درباره

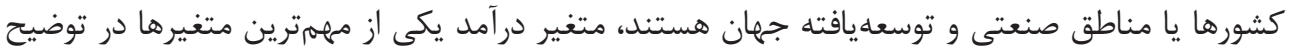

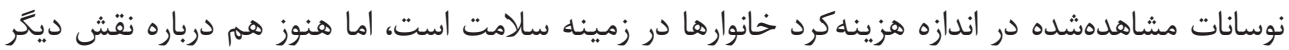

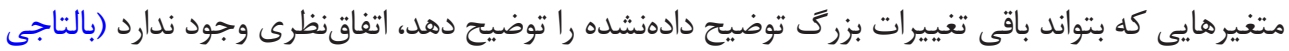

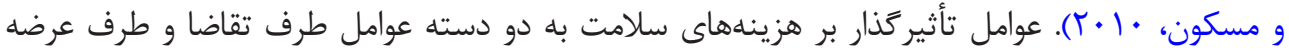

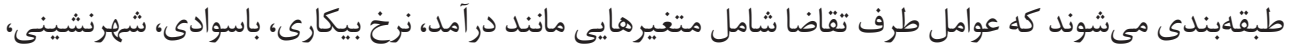

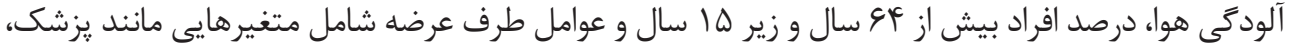

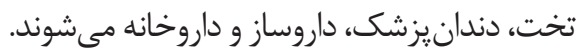

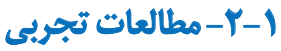

يس از نخسين مطالعه نيوهاووس (19VV) در زمينه در آمد و هزينههاى سلامت، تاكنون مطالعات بسيارى به منظور تعيين كشش درآمدى سلامت و تعيين لوكس يا ضرورى بودن سلامت به عنوان كالا انجام شده است دون.

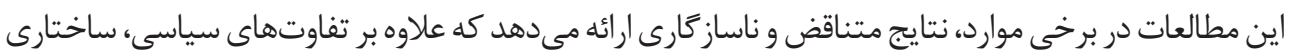

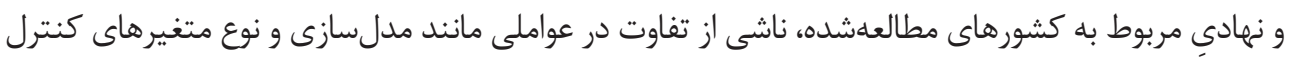

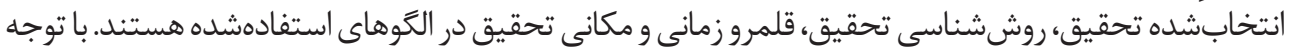

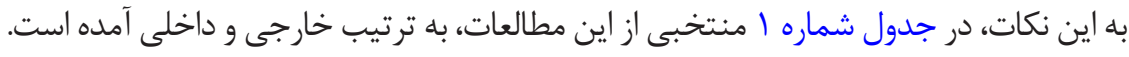

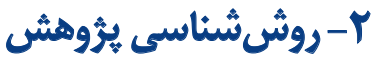

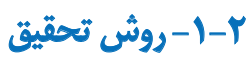

عدم اطمينان مدل هاى تجربى ممكن است از سه عامل ناشى شود: ا. عدم اطمينان نظرى، ؟ا. عدم اطمينان

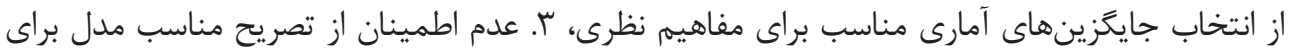

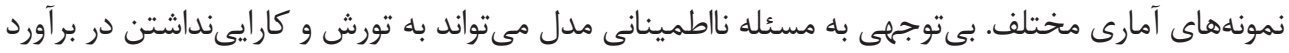

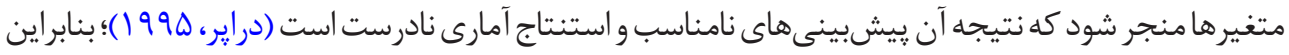

\section{Roemer's law}




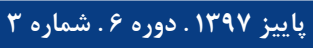

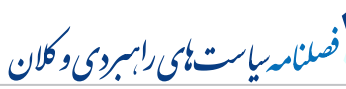

جدول ا. خلاصهاى از منتخب مطالعات خارجى و داخلى انجامشده در زميئه موضوع تحقيق

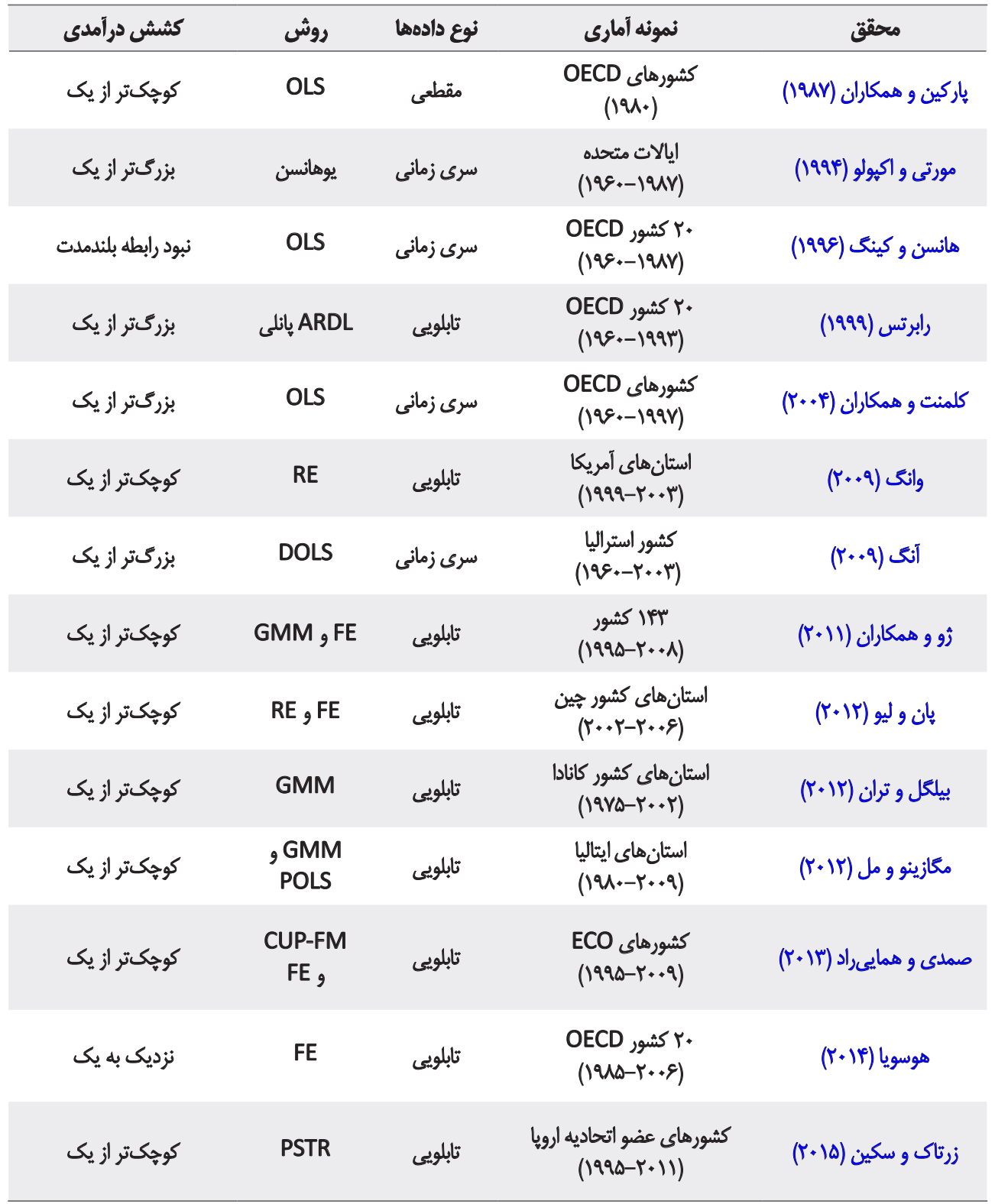

rar

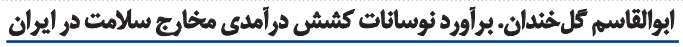




\begin{tabular}{|c|c|c|c|c|}
\hline كشئش درآمدى & روش & نوع دانsosl & نمونه آمارى & محقق مقت \\
\hline كوجكتر ازي يك & روانتاييلن & ت تابلويي & ג كشور, Yr-199.) OECD & ثيان و همكاران (r. (r) \\
\hline در هر دو نمونه كوجكثر & $R E, F E$ & ت تابلويى & 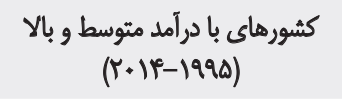 & بستامثت و شيمكا (T+lV) \\
\hline تزنديك به يك & يوهائسن و & سرى زمائي & 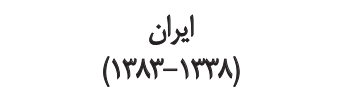 & بهشتى و سجودى (Y.V. (Y) \\
\hline كوجكتر از يك & DOLS & 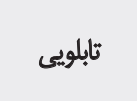 & 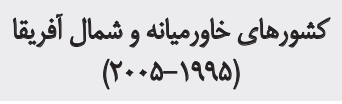 & مهراراو فضضائلى \\
\hline 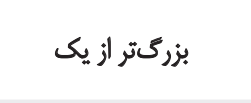 & DOLS & ت تابلويى & 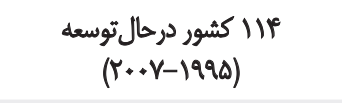 & $\begin{array}{c}\text { هـرآراو همكاران } \\
(r+1 T)\end{array}$ \\
\hline كوجه إتر ازيك & $\mathrm{FE}$ & ثابلويى & 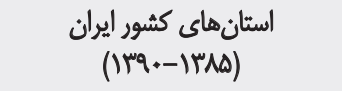 & رضايع و همكاران (؟1 +r) \\
\hline
\end{tabular}

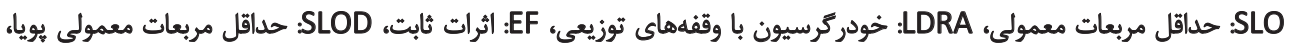

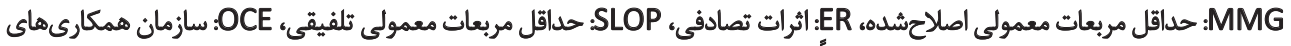

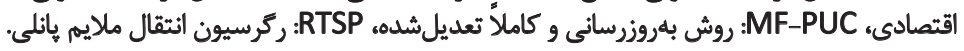
منبع: يافتههاي تحقيق بر اساس مطالعات تجربى.

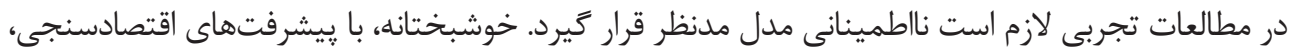

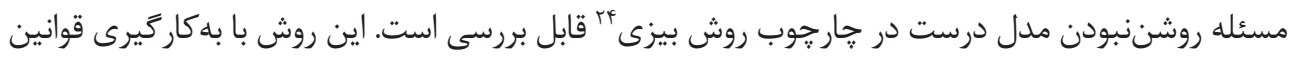

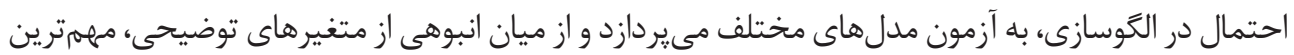

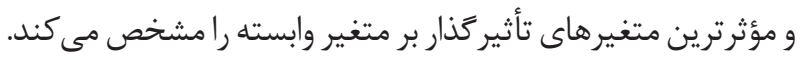

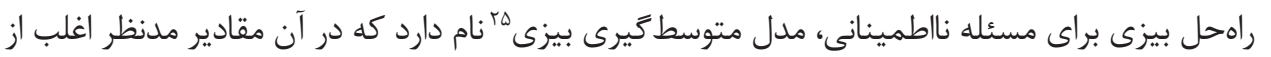

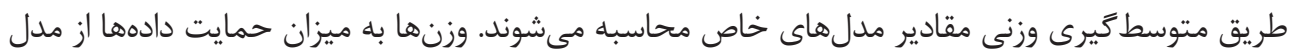

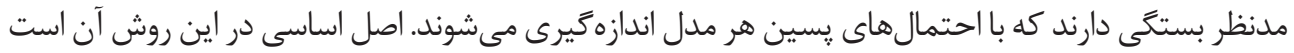

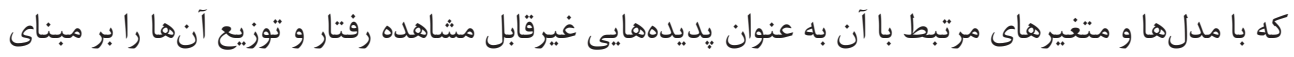

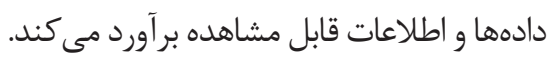
مدل متوسطگيرى به لحاظ مفهومى بسيار ساده است. اين روش اطلاعات نمونهاى موجود در تابع

25. Bayesian Model Averaging (BMA) 


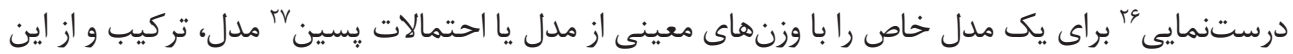

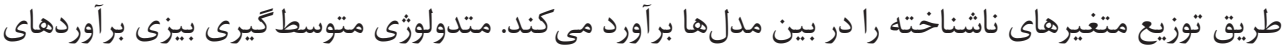

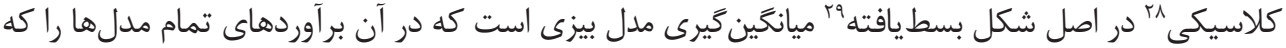

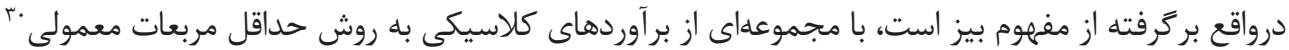

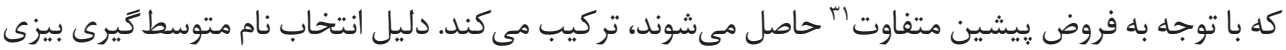

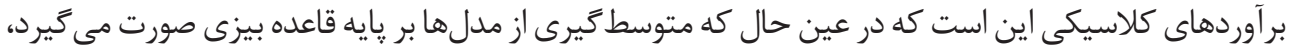

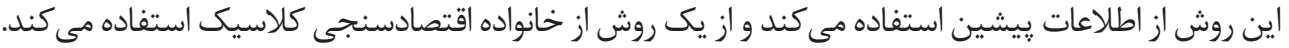

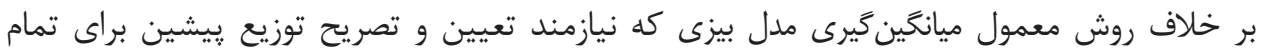

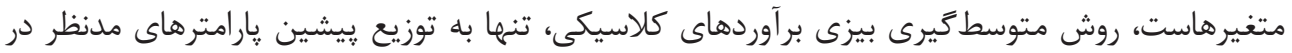

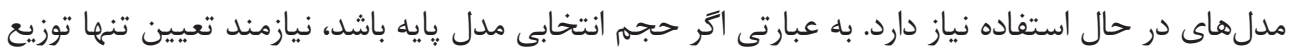

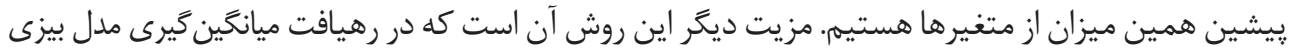

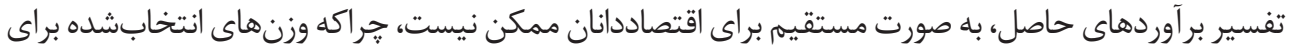

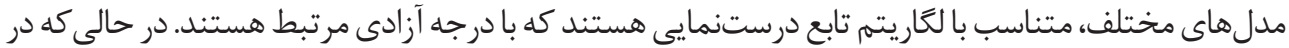

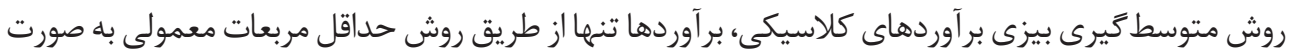

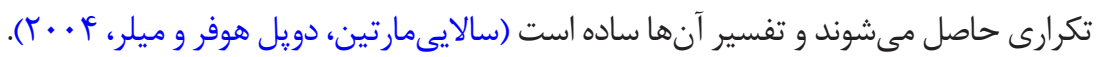

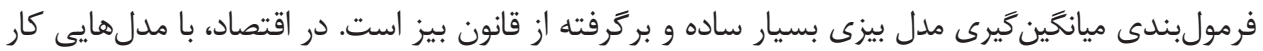

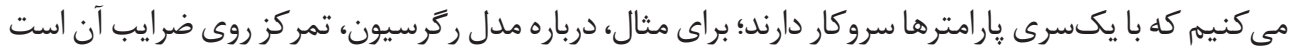

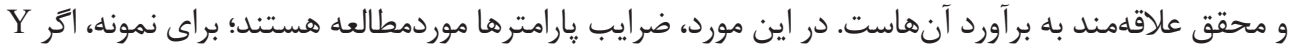

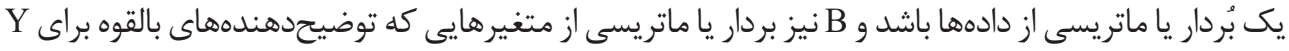

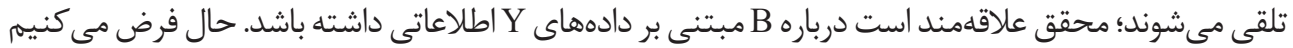

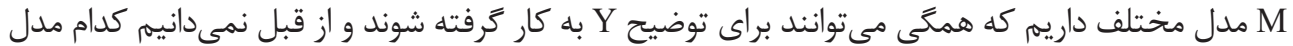

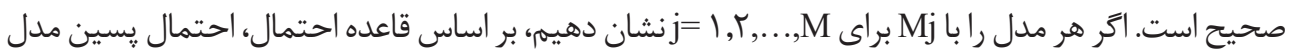

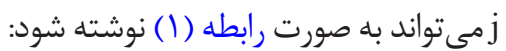

$\mathrm{P}\left(\mathrm{M}_{\mathrm{j}} \mid \mathrm{Y}\right)=\frac{\mathrm{P}\left(\mathrm{Y} \mid \mathrm{M}_{\mathrm{j}}\right) \cdot \mathrm{P}\left(\mathrm{M}_{\mathrm{j}}\right)}{\mathrm{P}(\mathrm{Y})}$

26. Likelihood

27. Posterior

28. Bayesian Averaging of Classical Estimates (BACE)

29. Bayesian Model Averaging (BMA)

30. Ordinary Least Squares (OLS)

31. Diffuse Priors 


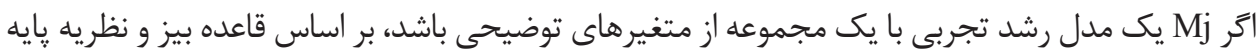

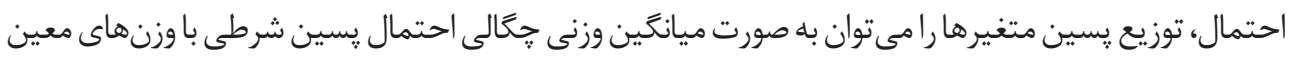

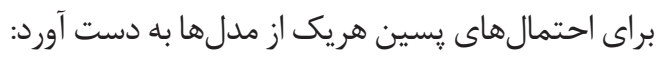

$\mathrm{P}(\theta \mid \mathrm{Y})=\sum_{\mathrm{j}=1}^{2^{\mathrm{k}}} \mathrm{P}\left(\mathrm{M}_{\mathrm{j}} \mid \mathrm{Y}\right) \cdot \mathrm{g}\left(\mathrm{B} \mid \mathrm{Y}, \mathrm{M}_{\mathrm{j}}\right)$

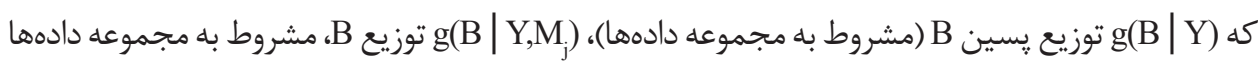

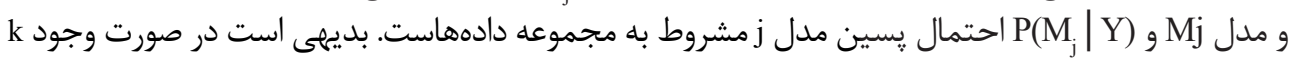

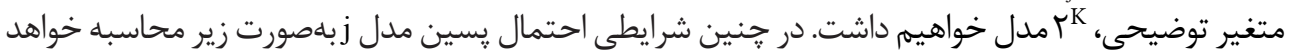

$P\left(M_{j} \mid Y\right)=P\left(M_{j}\right) \cdot w(j)$

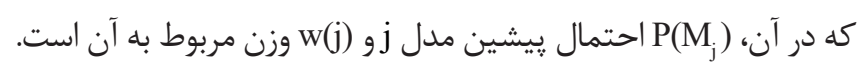

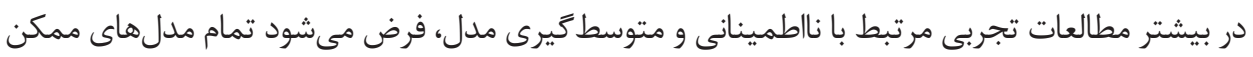

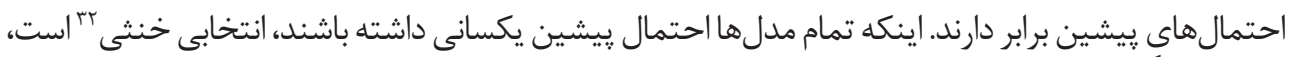

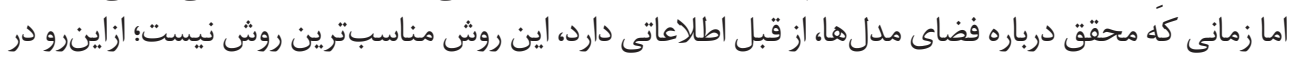

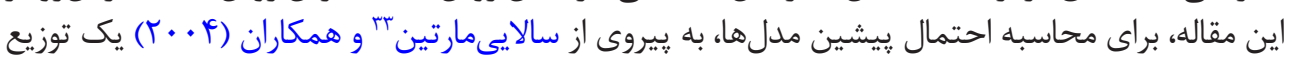

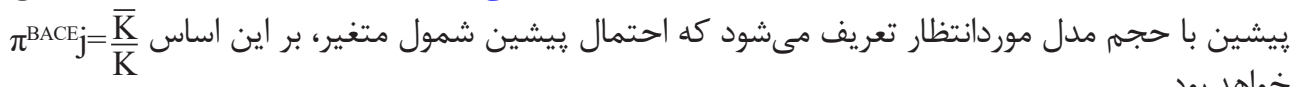
خواهد بود.

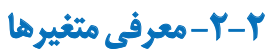

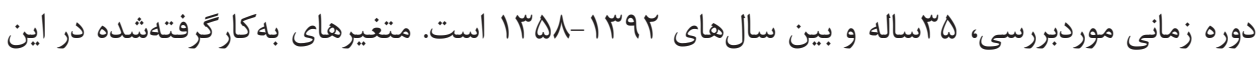

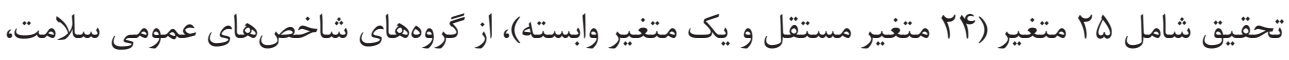

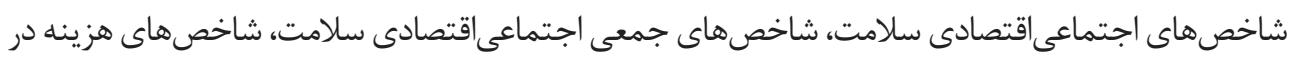

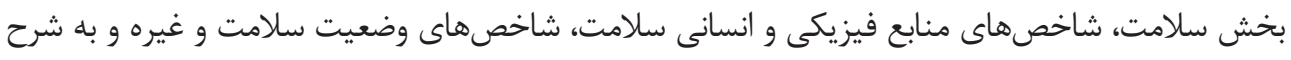

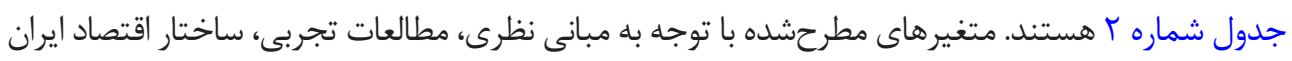

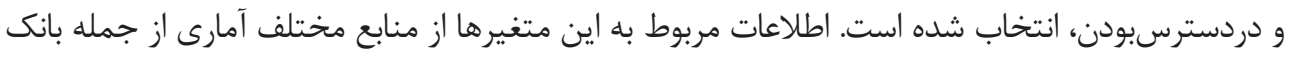

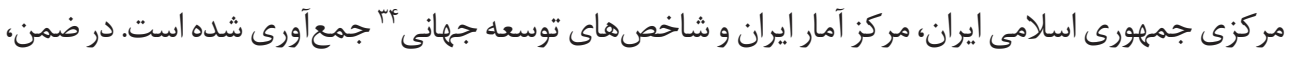

\section{Neutral}

33. Sala-i-Martin

34. World Development Index (WDI) 
تمامى متغيرها به صورت لعًاريتمى در نظر گرفته شدهاند، زيــرا استفاده از مقادير مطلق دادهها بهدليل نوسانات

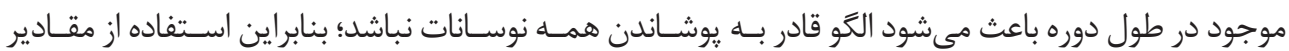

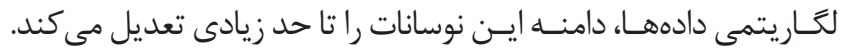

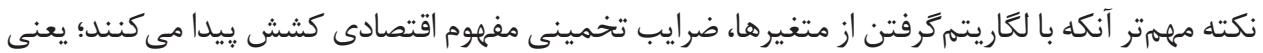

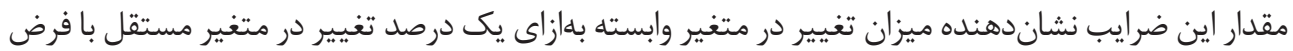

جدول r. متغيرهاى بهكار ترفته شده در تحقيق

\begin{tabular}{|c|c|c|c|c|}
\hline انتظارى & تعريف & متغير & رديف & 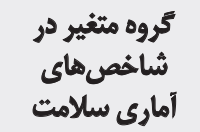 \\
\hline متغير وابسته & سرانه هزينههاى بخش سلامت & HE & . & - \\
\hline+ & توليد ناخالص داخلى سرانه (شاخص درآمد سرانه) & GDPpc & 1 & \multirow{3}{*}{ اجتماعىاقتصادهاى } \\
\hline 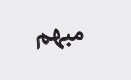 & درصد كل باسوادى در افراد بالاى ها سال & LIT & r & \\
\hline ميهم & نرخ تورج & INF & r & \\
\hline+ & سرائه تعداد يز شكان بهازاى هر +ا هزار نفر جمعيت & PHY & f & \multirow{2}{*}{ فيزيكى هاي منابع انسائى } \\
\hline+ & 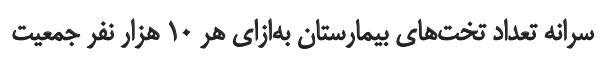 & BED & $\Delta$ & \\
\hline مبهم & اميد به زندكى در بدو تولد & LE & 8 & شاخصهاى وضعيت \\
\hline+ & سيهم هزيئههاى عمومى سلامت از كل هزيئههاى سلامت & PHE & $\checkmark$ & شاخص هاى هزينه \\
\hline مبرم & ن & UNE & $\Lambda$ & \multirow{3}{*}{ 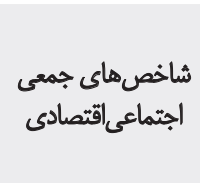 } \\
\hline- & درول جمعيت با دسترسى به آب سالم & SW & 9 & \\
\hline- & درصد جمعيت با دسترسى به فاضلابهاي بهلاشتى & HW & 1. & \\
\hline مبهم & جمعيت كل & POP & 11 & \multirow{6}{*}{ شاخصهاي عمومى } \\
\hline+ & 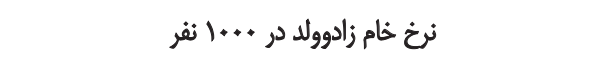 & BIR & ir & \\
\hline مبهم & نُخ خام مركومير در +... نفر & MOR & ri & \\
\hline مبه & نزخ مشاركت نيروى كار زنان & FLP & if & \\
\hline+ & سهمر جمعيت شهرى از كل جمعيت (نرخ شهرنشينى) & UP & 10 & \\
\hline+ & 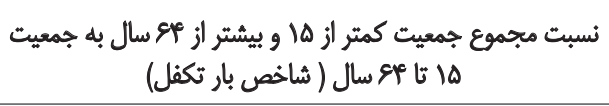 & DR & 18 & \\
\hline
\end{tabular}




\begin{tabular}{|c|c|c|c|c|}
\hline أنظارى علامث & تعريف & مثغير & رديف & 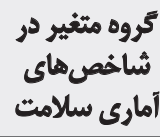 \\
\hline+ & وقفه مثغير وابسته & HE $(-1)$ & IV & \\
\hline+ & سبهم هزينههاي دولت از توليد ناخالص داخليى (شاخص اندازه & $\mathrm{GE}$ & M & \\
\hline+ & سهم درأمدهاي نفتى از توليد ناخالص داخلى & OIL & 19 & \\
\hline+ & ميزان انتشار كاز كربن دىاكسيد (شاخص آلودكى هوا) & $\mathrm{CO}_{\mathrm{r}}$ & r. & $\frac{3}{28}$ \\
\hline+ & ميزان ذرات معلق با قطر كمثر از • أميكرومتر (شاخص ألودكى & PM & ri & 娄 \\
\hline+ & شدت مصرف ائرئى & El & r & \\
\hline+ & روند ز مانى & $\mathrm{T}$ & $m$ & \\
\hline+ & 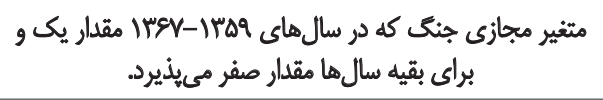 & WAR & m & \\
\hline
\end{tabular}

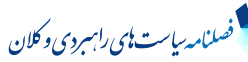

ثبات ساير متغيرهاست و مستقل از واحد اندازهخيرى است. با درنظر عرفتن اين متغيرها در كنار هم، اين امكان

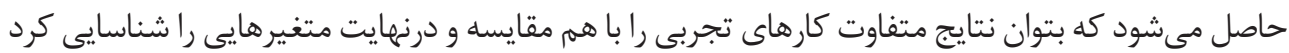

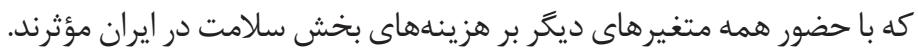

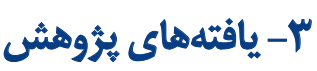

براى حصول نتيجه بايد محاسبات روى تمام مدلها در فضاى مدل انجام شود. با توجه به تعداد متغيرهاى

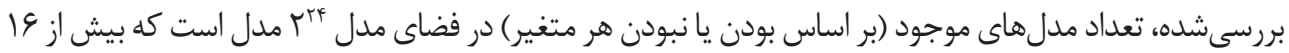

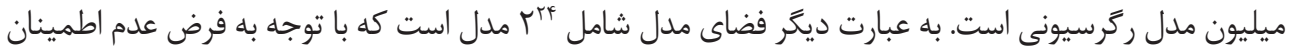

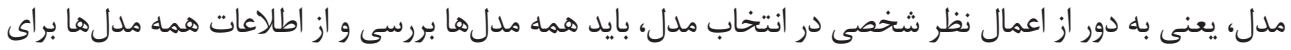

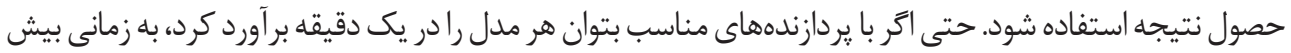

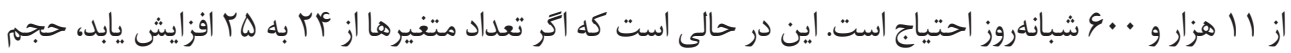

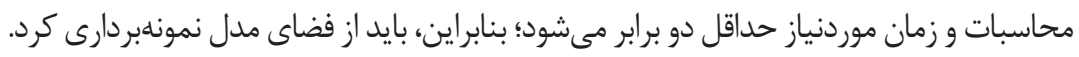

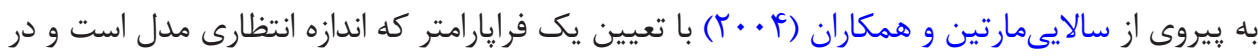

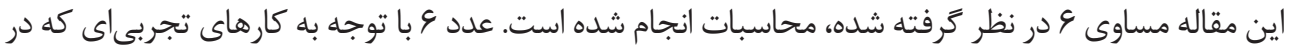

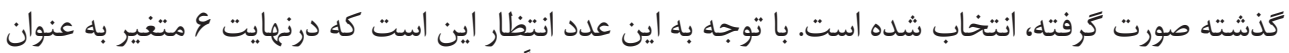

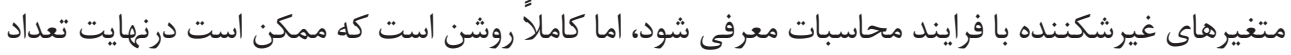




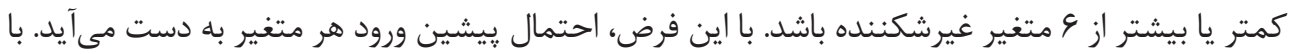

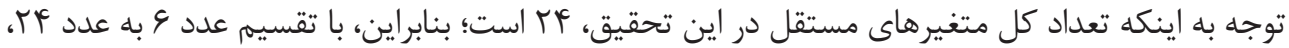

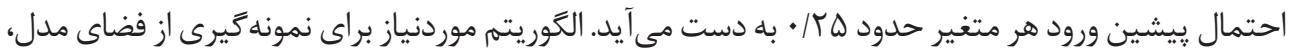

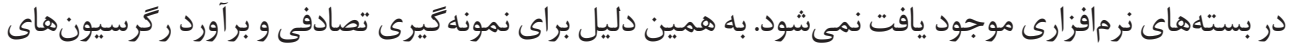

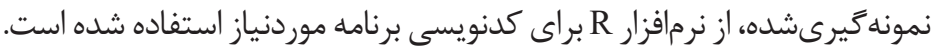

در ابتدا با بهدستآوردن نمونهاى شامل · ل هزار رَرسيون از فضاى مدل، ضرايب و انحراف معيار متغيرها

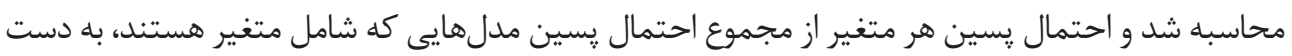

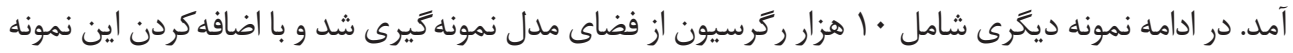

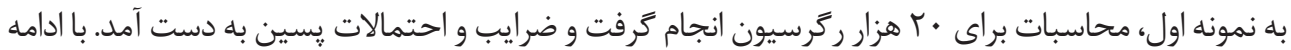

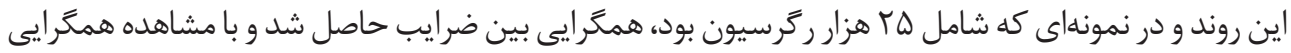

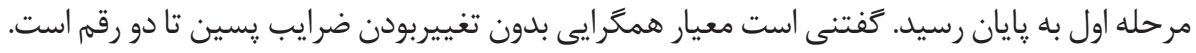

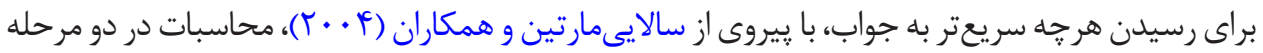

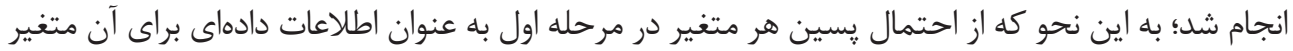

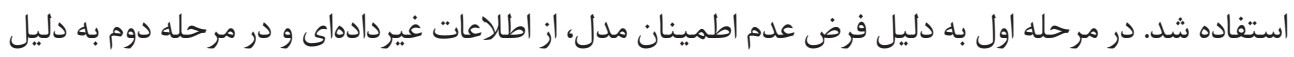

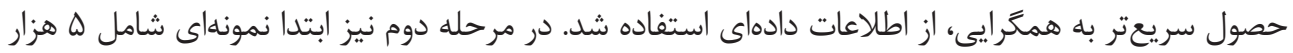

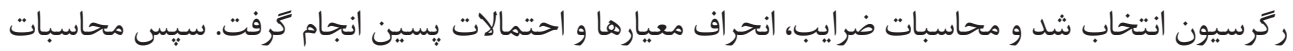

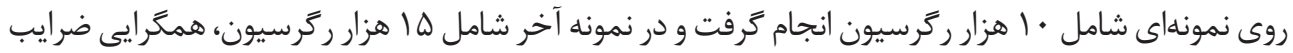

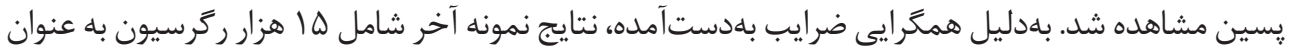

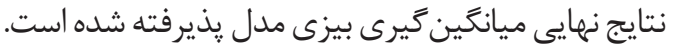

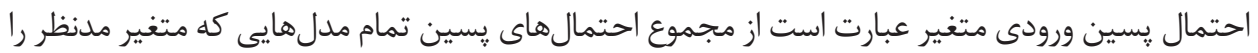

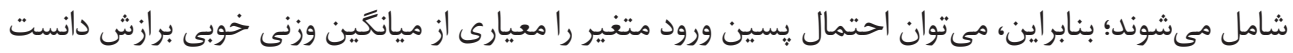

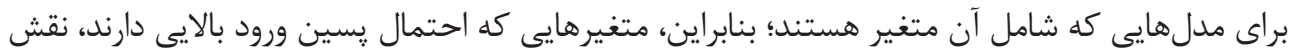

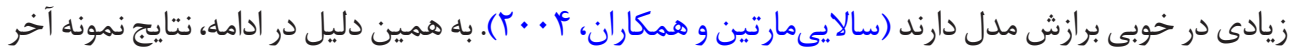

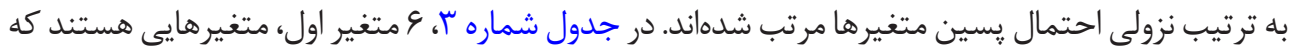

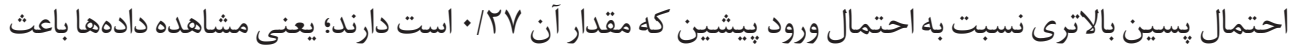

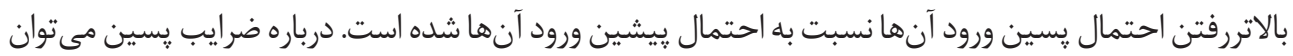

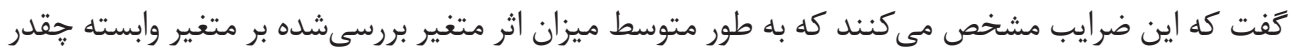

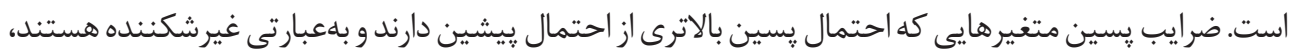

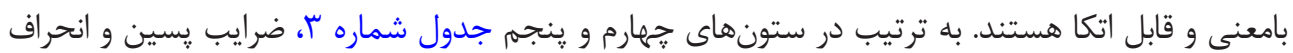

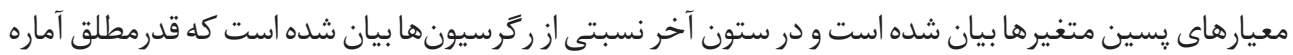

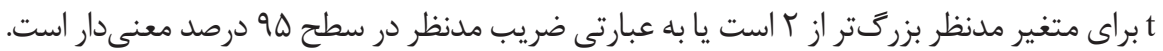




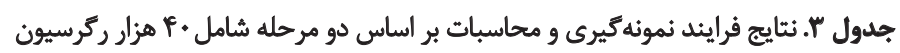

\begin{tabular}{|c|c|c|c|c|c|}
\hline فسبتى ازٔ روكر سيونها با & انحراف معيار يسين & ضريب بسين & احتمال يسين & متغير & رديف \\
\hline $.19 v 0$ & $.1 \cdot V 0$ & $\cdot N \cdot 1$ &.$/ 41$ & GDPpc & 1 \\
\hline.$/ 970$ &.$/ M T A$ & $\mid / T A 1$ & ./AYD & UP & $r$ \\
\hline.$/ 9 T V$ & 1.gr &.$/ r q 1$ &.$/ 110$ & PHE & $r$ \\
\hline.$/ V I D$ & 1.94 & ./TE & $\cdot / \Delta \cdot 1$ & $\mathrm{DR}$ & $r$ \\
\hline - larr &.$/ 1 \mathrm{HF}$ & $\cdot r \cdot r$ & - IFAD & PHY & $\Delta$ \\
\hline - par & . $1 . r o$ & -.1 .89 & $\cdot / r A 1$ & UNE & $\varepsilon$ \\
\hline - MAY & $\cdot 1 \cdot r A$ &.$/ 409$ &.$/ \pi F a$ & $\mathrm{HE}(-1)$ & $\checkmark$ \\
\hline . MEA & $\cdot|\cdot 1|$ &.$/ 1 F A$ & . MTA & LIT & $A$ \\
\hline $.1 .9 r$ & $+1+A r$ & -.1 .89 &.$/ N r$ & INF & 9 \\
\hline.$/ 119$ & - Isto & $1 / \Delta Q A$ & +||$\Delta \mid$ & POP & 1. \\
\hline.$/ 1 F F$ & $+1+f 0$ & .11 .9 & . IFT & $\mathrm{CO}_{\mathrm{r}}$ & 11 \\
\hline$\cdot / \cdot \Delta r$ & $\cdot|| r \mid$ &.$-|+r|$ & ./Irr & SW & ir \\
\hline. $\mid r e 1$ & $.1 \cdot r \Delta$ & $\cdot 1 \cdot \Delta \Delta$ &.$/ 1 Y 8$ & $\mathrm{~T}$ & ir \\
\hline$\cdot|\cdot A|$ &.$/ 0 Y$ & .1 .08 &.$/ 1 Y \Delta$ & WAR & if \\
\hline.$/ M$ & $+1+4 \lambda$ & $+1+\Delta 1$ &.$/ 110$ & PM10 & 10 \\
\hline $1+\sqrt{9}$ & $* n$ & $-+/ 1 N$ & $+1+\infty$ & BED & is \\
\hline Pler & . IDAT &.$- / 1 W$ & $\cdot / r+r$ & LE & iv \\
\hline$\cdot 1 \cdot 11$ & V/DAP & .11 .8 &.$/ 1 \cdot 1$ & FLP & 11 \\
\hline .1018 & I/AAY &.$/ 188$ & $.1 .1 \Delta$ & EI & 19 \\
\hline $.10 . r$ & $.1 \cdot f a$ & $-.1 \cdot \cdot r$ & $.1+A F$ & $\mathrm{HW}$ & r. \\
\hline.$/ .1 r$ & $+1+11$ & $+1+r \Delta$ & I.Ar & MOR & rI \\
\hline .1 .10 & $.1 .+8$ & $.1+11$ & .1 .81 & OIL & M \\
\hline $.1+.1$ & $.1+1 \Delta$ & $1 *+\varphi$ & $.1 \cdot \Delta \Delta$ & BIR & זr \\
\hline .10 .1 & .1 .95 & $.1 .+4$ &.$/ .4 q$ & GE & MP \\
\hline
\end{tabular}


از اين نظر كه در حضور بقيه متغيرها انتظار ما از ورود و متغير اول به ركرسيون افزايش يافته است، اين

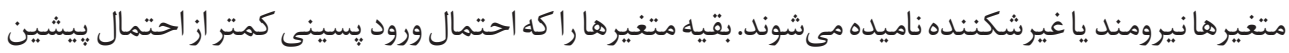

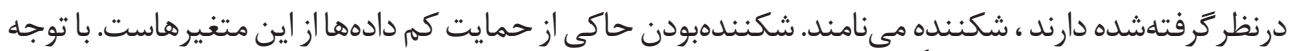

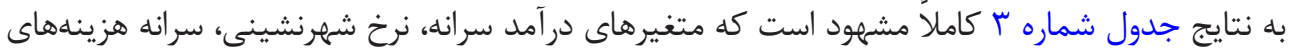

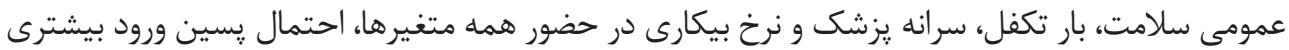

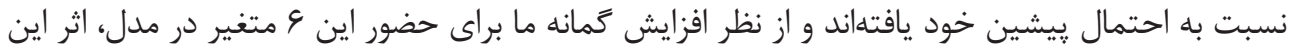

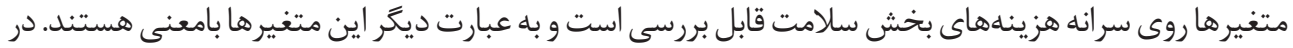
بين و متغير بلهدستآمده، همه متغيرها به جز

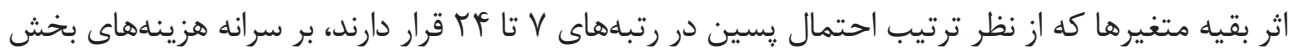

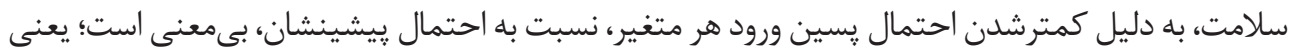

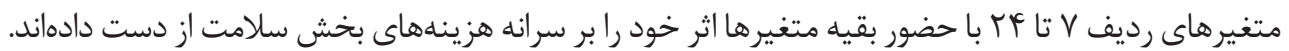
بر اساس نتايج جدول شماره ؟، متغير درآمد سرانه كه موضوع اصلى اين تحقيق است، با احتمال حدود 91 ـ ـ

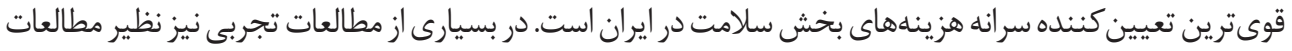

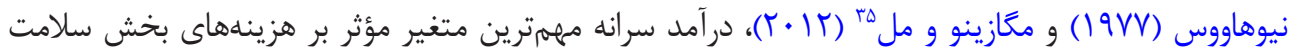

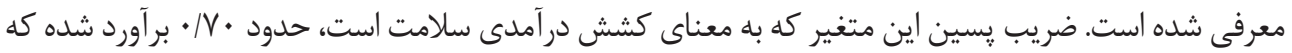

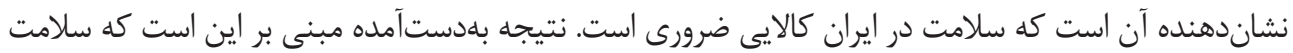

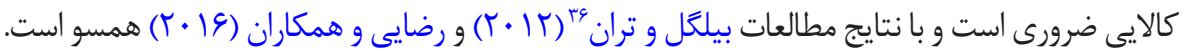
نرخ شهرنشينى با احتمال يسين حدود ب9 • دومين متغير مؤثر بر سرانه هزينههاى بخش سلامت در ايران

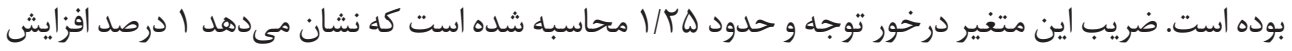

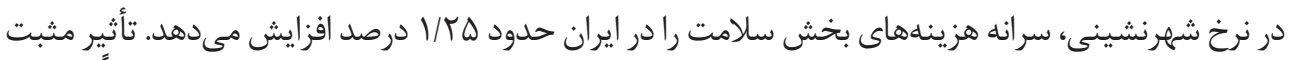
شهرنشينى روى هزينههاى سلامت از دو ديد

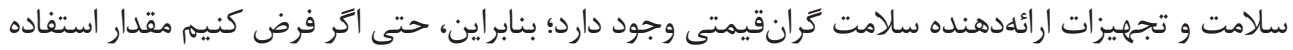

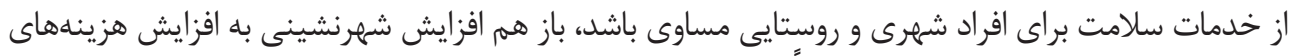

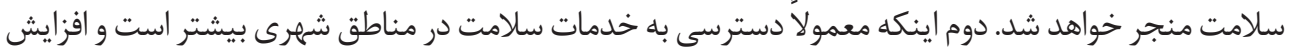

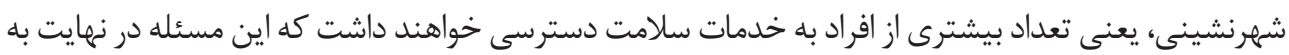

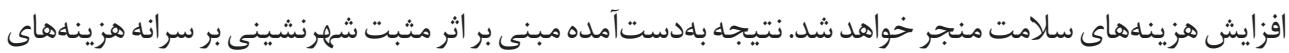

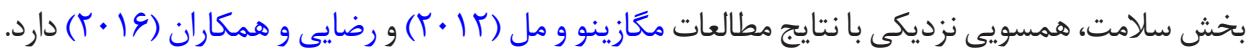
سرانه هزينههاى عمومى سلامت با احتمال يسين حدود AY/ • سومين متغير مؤثر بر سرانه هزينههاى بخش

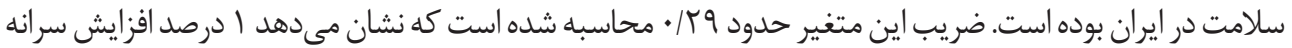

35. Magazzino and Mele

36. Bilgel and Tran 


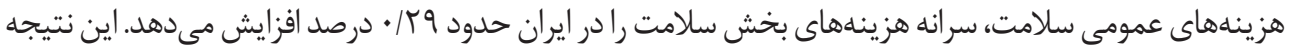

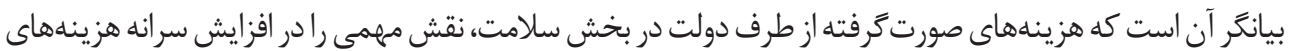

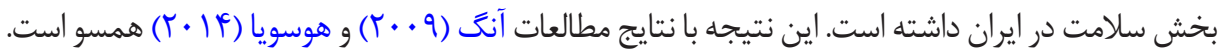

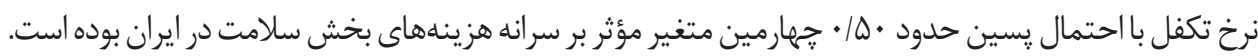

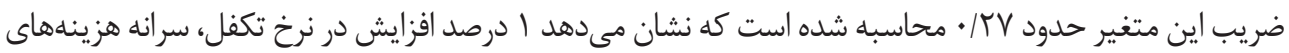

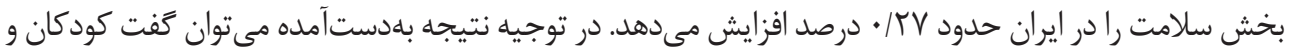

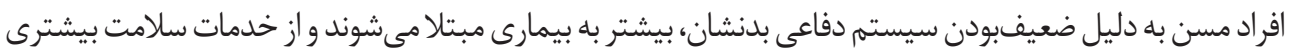

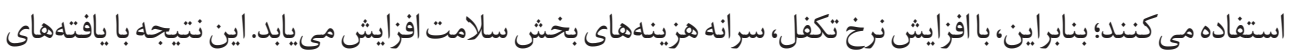

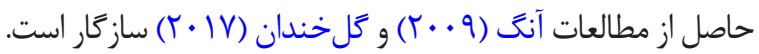

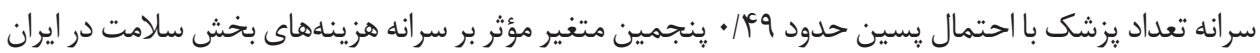

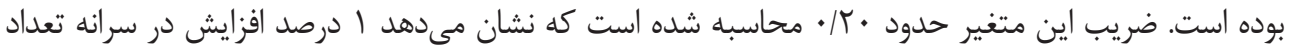

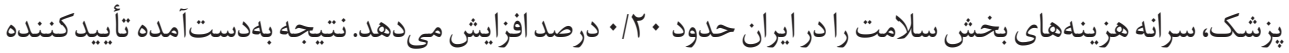

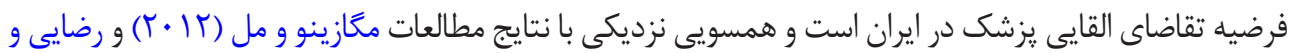

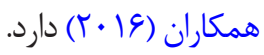

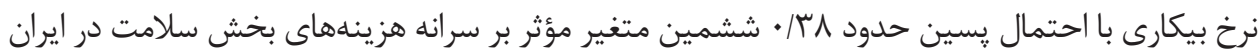

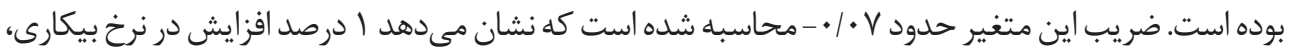

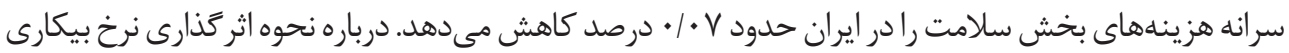

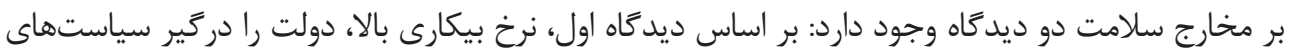

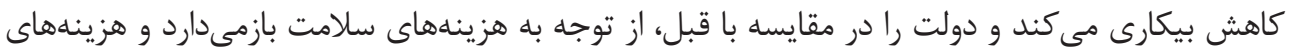

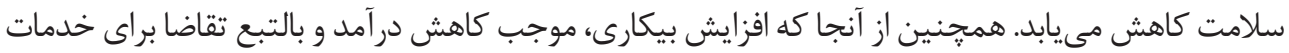

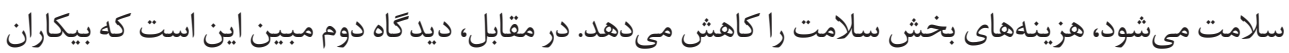

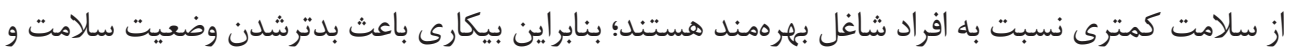

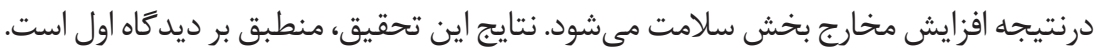

\section{ع-بحث و نتيجلكيرى}

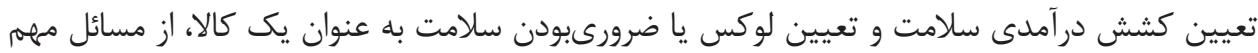

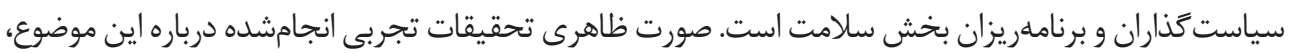

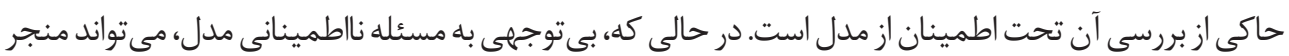

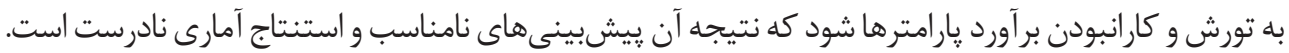

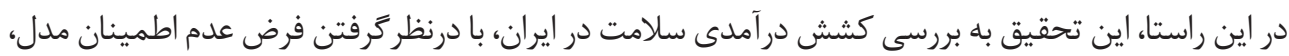

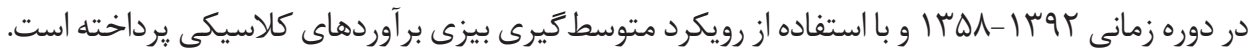


با انجام محاسبات و بررسى اثر ع آب عامل روى سرانه هزينههاى بخش سلامت در ايران، مشخص شد در آمد سرانه

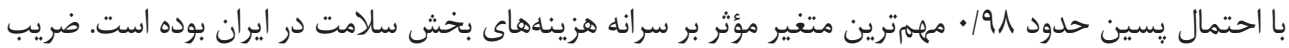

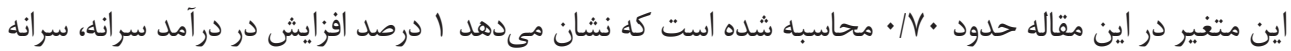

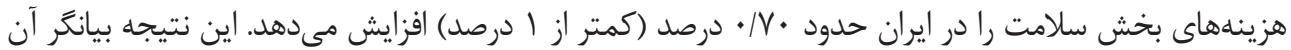

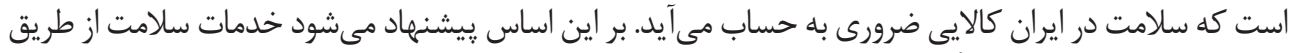

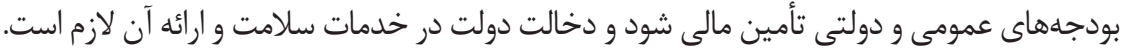

بر اساس ديكر نتايج تحقيق نيز متغيرهاى نرخ شهرنشينى، سرانه هزينههاى بهداشت عمومى، بار تكفل، سرانه

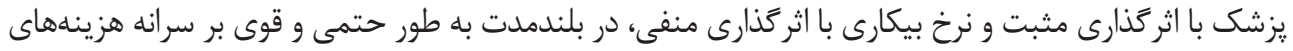

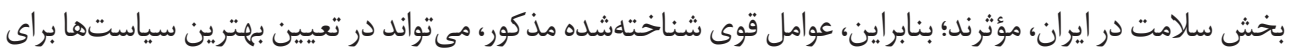

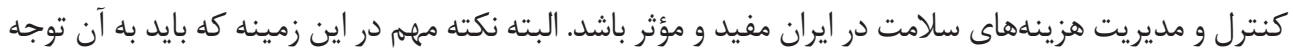

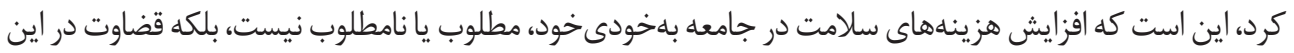

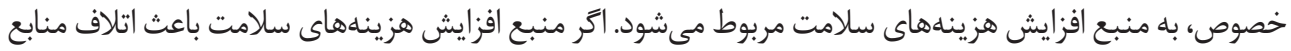

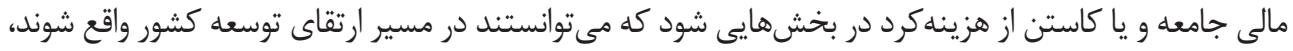

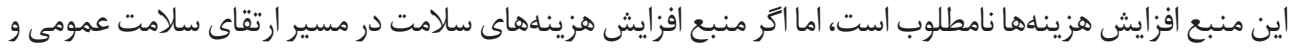

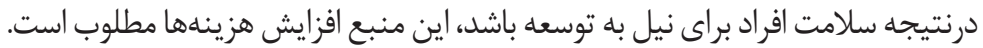

با توجه به اين موضوع و بر اساس نتايج بهدستآمده، به سياست گذذاران كشور، اعمال سياستهايى جدى دئ

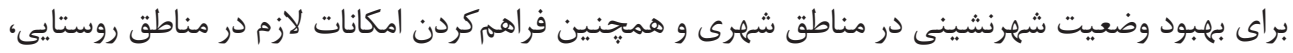

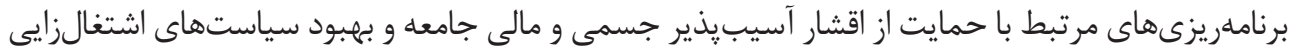

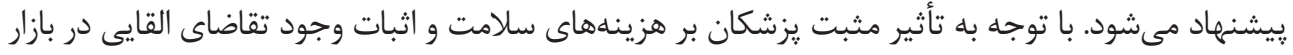

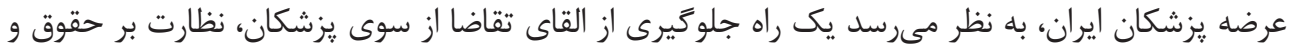

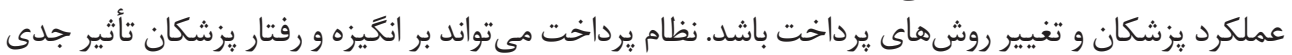

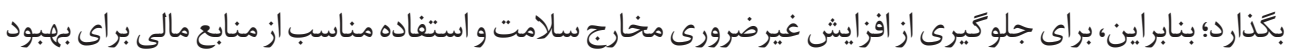

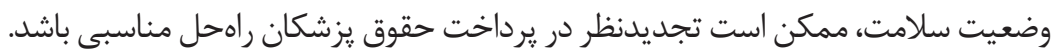

ملاحظات اخلاقى

$$
\text { تعامى مالى }
$$

بنا به اظهار نويسند 


\section{References}

Ang, J. B. (2009). The determinants of health care expenditure in Australia. Applied Economics Letters, 17(4), 639-44.

Baker, L. C., \& Wheeler, S. K. (2000). Managed care and technology diffusion the case of MRI. Health Affairs, 17(5), $195-207$. [PMID]

Baltagi, B. H., \& Moscone, F. (2010). Healthcare expenditure and income in the OECD Reconsidered: Evidence from panel data. Economic Modelling, 27(4), 804-11.

Beheshti, M. B., \& Sojoodi S. (2007). [The relationship between health expenditure and GDP in Iran (Persian)]. Journal of Quantitative Economics, 4(4), 115-36.

Berndt, E. R., David M., Cutler, D. M., Richard, G., Frank, R. G., Griliches, Z., et al. (2000). Medical care prices and output. In A. J. Culyer, \& J. P. Newhouse (Eds.). Handbook of Health Economics (pp. 119-180). Amsterdam: Elsevier. [DOI:10.1016/ S1574-0064(00)80162-6]

Bilgel, F., \& Tran, K. C. (2012). The determinants of Canadian provincial health expenditures: Evidence from a dynamic panel. Applied Economics, 45(2), 201-12. [DOI:10.1080/00036846.2011.597726]

Bustamante, A. V., \& Shimoga, S. V. (2017). Comparing the income elasticity of health spending in middle-income and high-income countries: The role of financial protection. International Journal of Health Policy and Management, 7(3), $255-63$. [DOI:10.15171/ijhpm.2017.83]

Clemente, J., Marcuello, C., Montanes, A., \& Pueyo, F. (2004). On the international stability of health care expenditure functions: Are government and private functions similar? Journal of Health Economics, 23(3), 589-613. [DOI:10.1016/j.jhealee co.2003.08.007]

Culyer, A. J. (1988). Health care expenditures in Canada: myth and reality; past and future. Toronto: Canadian Tax Foundation.

Di Matteo, L. (2003). The income elasticity of health care spending: A comparison of parametric and nonparametric approaches. The European Journal of Health Economics, 4(1), 20-9. [DOI:10.1007/s10198-002-0141-6]

Di Matteo, L. (2004). What drives provincial health expenditure? Canadian Tax Journal, 52(4), 1102-20.

Draper, D. (1995). Assessment and propagation of model uncertainty. Journal of the Royal Statistical Society, 57(1), 45-97.

Gerdham, U. G., Sogaard, J., Andersson, F., \& Jonsson, B. (1992). An econometric analysis of health care expenditure: A cross-section study of the OECD countries. Journal of Health Economics, 11(1), 63-84. [DOI:10.1016/0167-6296(92)90025-V]

Gerdham, U., \& Lothgren, M. (2000). New panel results on co-integration of international health expenditure and GDP. Applied Economics, 34(13), 1679-86. [DOI:10.1080/00036840110116397]

Getzen, T. E. (1992). Population aging and the growth of health expenditures. Journal of Gerontology, 47(3), S98-S104. [DOI:10.1093/geronj/47.3.S98] [PMID]

Getzen, T. E. (2000). Healthcare is an individual necessity and a national luxury: Applying multilevel decision models to the analysis of health care expenditures. Journal of Health Economics, 19(2), 259-70. [DOI:10.1016/S0167-6296(99)00032-6]

Golkhandan, A. (2017). [Measuring the impacts of air pollution on health costs in Iran (Persian)]. Health Research Journal, 2(3), 157-66.

Grossman, M. (1972). On the concept of health capital and the demand for health. Journal of Political Economy, 80(2), $223-55$. [DOI:10.1086/259880] 
Hansen, P., \& King, A. (1996). The determinants of health care expenditure: A co-integration approach. Journal of Health Economics, 15(1), 127-37. [DOI:10.1016/0167-6296(95)00017-8]

Hartwig, J. (2008). What drives healthcare expenditure? Baumol's model of unbalanced growth revisited. Journal of Health Economics, 27(3), 603-23. [DOI:10.1016/j.jhealeco.2007.05.006] [PMID]

Hosoya, K. (2014). Determinants of health expenditures: Stylized facts and a new signal. Modern Economy. 5(13), 1171-80. [DOI:10.4236/me.2014.513109]

Liu, C., \& Maheu, J. M. (2009). Forecasting realized volatility: A Bayesian Model-Averaging approach. Journal of Applied Econometrics, 24(5),709-33. [DOI:10.1002/jae.1070]

Magazzino, C., \& Mele, M. (2012). The determinants of health expenditure in Italian regions. International Journal of Economics \& Finance, 4(3), 61-72. [DOI:10.5539/ijef.v4n3p61]

Martín J. M, Puerto, M., \& Dolores M. (2011). Review of the literature on the determinants of healthcare expenditure. Applied Economics, 43(1), 19-46. [DOI:10.1080/00036841003689754]

Mehrara, M., \& Fazaeli, A. (2009). [A study on health expenditures in relation with economics growth in Middle East and North Africa (MENA) countries (Persian)]. Journal of Health Administration, 12(35), 49-60.

Mehrara, M., Sharzei, Gh., \& Mohaghegh, M. (2012). [study of the relationship between health expenditure and environmental quality in developing countries (Persian)]. Journal of Health Administration, 14(46), 79-88.

Murthy, N. R., \& Ukpolo, V. (1994). Aggregate health expenditure in the United States. Applied Economics, 26(8), 797-802. [DOI:10.1080/00036849400000094]

Newhouse, J. P. (1977). Medical care expenditure: A cross-national survey. Journal of Human Resources, 12(1), 115-25. [DOI:10.2307/145602] [PMID]

Newhouse, J. P. (1992). Medical care costs: How much welfare loss. Journal of Economic Perspective, 6(3), 3-21. [DOI:10.1257/ jep.6.3.3] [PMID]

Okunade, A. A., \& Murthy, V. R. (2002). Technology as a major driver of health care costs, a co-integration analysis of the Newhouse conjecture. Journal of Health Economics, 21(1), 147-59. [DOI:10.1016/S0167-6296(01)00122-9]

Okunade, A. A., Karakus, M. C., \& Okeke, C. (2004). Determinants of health expenditure growth of the OECD countries: Jackknife re sampling plan estimates, Health Care Management Science, 7(3), 173-83. [DOI:10.1023/B:HCMS.0000039380.42784.20]

Zortuk, M., \& Ceken, S. (2015). The relationship between health care expenditures and income in the selected transition economies: A panel smooth transition regression analysis. Romanian Journal of Economic Forecasting, 18(2), 105-18

Pan, J., \& Liu, G. G. (2012). The determinants of Chinese provincial government health expenditures: Evidence from 2002-2006 data. Health Economics, 21(7), 757-77. [DOI:10.1002/hec.1742] [PMID]

Parkin, D., Mcguire, A., \& Yule, B. (1987). Aggregate healthcare expenditure and national income: Is health care a luxury good? Journal of Health Economics, 6(2), 109-27. [DOI:10.1016/0167-6296(87)90002-6]

Rezaei, S., Dindar, A. A., \& Rezapour, A. (2016). [Health care expenditures and their determinants: Iran provinces (2006-2011) (Persian)]. Journal of Health Administration, 19(63), 81-90.

Roberts, J. (1999). Sensitivity of elasticity estimates for OECD health care spending: Analysis of a dynamic heterogeneous data field. Health Economics, 8(5), 459-72. [DOI:10.1002/(SICI)1099-1050(199908)8:53.0.CO;2-U] 
Sadeghi, S. K., Motafekker Azad, M. A., \& Jalilpour, S. (2014). [Investigating main determinants of private healthcare expenditure and their effects between different income levels in Asian countries (Persian)]. Social Welfare Quarterly, 14(53), 55-75

Sala-i-Martin, X., Doppelhofer, G., \& Miller, R. (2004). Determinants of long-term growth: A Bayesian Averaging of Classical Estimates (BACE) approach. The American Economic Review, 94(4), 813-35. [DOI:10.1257/0002828042002570]

Samadi A., \& Homaie Rad, E. (2013). Determinants of healthcare expenditure in Economic Cooperation Organization (ECO) countries: Evidence from panel co-integration tests. International Journal of Health Policy and Management, 1(1), 63-8. [DOI:10.15171/ijhpm.2013.10] [PMID]

Seshamani M., \& Gray, A. M. (2004). A longitudinal study of the effects of age and time to death on hospital costs. Journal of Health Economics, 23(2), 217-35. [DOI:10.1016/j.jhealeco.2003.08.004] [PMID]

Tian, F., Gao, J., \& Yang, K. (2016). A quintile regression approach to panel data analysis of health care expenditure in OECD countries. Working Paper. Caulfield East: Monash Business School.

Wang, Z. (2009). The determinants of health expenditures: Evidence from US state-level data. Applied Economics, 41(4), 429-35. [DOI:10.1080/00036840701704527]

Weil, T. P. (1995). Comparisons of medical technology in Canadian, German and U.S hospitals. Hospital and Health Services Administration, 40(4), 524-33. [PMID]

Wilkinson, R. J. (1996). Unhealthy societies, the afflictions of inequality. Abingdon: Routledge.

Xu, K., Saksena, P., \& Holly, A. (2011). The determinants of health expenditure A country-level panel data analysis. Geneva: World Health Organization.

Zweifel, P., Felder, S., \& Meiers, M. (1999). Ageing of population and health care expenditure: A red herring? Health Economics, 8(6), 485-96. [DOI:10.1002/(SICI)1099-1050(199909)8:63.0.CO;2-4] 
This Page Intentionally Left Blank 